\title{
A pandemia do coronavírus: um produto da dinâmica global do capitalismo que impacta sobre a classe trabalhadora
}

Renata Venturim Bernardino ${ }^{1}$

Antunes, Ricardo. Coronavírus: o trabalho sob fogo cruzado. São Paulo: Boitempo, 2020, 51 p.

Artigo enviado em julho de 2021

Artigo aprovado em setembro de 2021

Como parte da série especial, 'Pandemia Capital' da Boitempo trata-se de uma obra curta, na qual o autor Ricardo Antunes traz uma abordagem objetiva e consistente sobre o mundo do trabalho, a crise estrutural do capital e as relações capitalistas destrutivas; somados à explosão da pandemia global do coronavírus que tem gerado impactos e consequências profundas e nefastas para a classe trabalhadora, que se encontra em intenso fogo cruzado.

Vemos neste livro que Ricardo Antunes enfoca a relação entre a pandemia do coronavírus e o sistema capitalista atual, a partir de uma abordagem marxista, dividindo sua obra em cinco capítulos: 1) "Mundo às vésperas da pandemia"; 2) "Sistema de metabolismo antissocial do capital cuja normalidade é a destrutividade"; 3) "A pandemia do capital e o (des)valor do trabalho"; 4) "Qual será o futuro do trabalho?"; e 5) "Um imperativo vital contra um mundo letal".

Inicialmente, o autor se refere a um processo destrutivo gerado pela globalização produtiva, que não se restringe apenas a países do Terceiro Mundo. Como o tempo e o espaço estão em frequente mutação, na fase de mundialização do capital, vem ocorrendo uma 
ampliação das novas modalidades de trabalhos e dos "novos proletários" (ANTUNES, 2018) em diferentes países, tanto na indústria, quanto na agricultura, mas especialmente no chamado setor de serviços, o que vem ampliando ainda mais o processo de miserabilidade de amplas parcelas da classe trabalhadora.

No caso do Brasil, o autor destaca que sempre foram vivenciadas formas intensas de exploração do trabalho e de precarização ilimitada, de subemprego e desemprego, gerando consequências sociais ainda mais perversas. Portanto, antes mesmo dessa brutal pandemia (coronavírus) já se presenciava a corrosão, o desmoronamento e a eliminação dos direitos sociais do trabalho.

Utilizando-se da metáfora de formulação marxiana, adaptada por István Mészáros (2002), o autor afırma que, cada vez mais, a “metabolização" do capital é necessária para a superexploração do trabalho, visto que o sistema capitalista é "autofágico". E considera que o sistema de metabolismo social do capital se constitui pelo tripé interrelacional entre capital, trabalho assalariado e Estado, indicando que a eliminação desse sistema somente será possível pela extinção desses três elementos estruturantes. Contudo, a sua superação é algo complexo e difícil tendo em vista sua lógica expansionista e o modus operandi do capital serem conformados pela extração crescente de mais-valor, sendo destrutivo, ilimitado e incontrolável.

O autor aponta que já no final da década 1960 se deflagrava o contexto de crise estrutural do sistema do capital e da tendência de redução do trabalho vivo pela substituição das atividades tradicionais por ferramentas automatizadas e robotizadas (trabalho morto), sob o comando informacional-digital. Como resultado do domínio das corporações globais financeirizadas, o capital vem precarizando o trabalho, desempregando parcelas imensas e ampliando o exército sobrante de força de trabalho, sem a extinção completa da atividade humana laborativa, pois o capital não se valoriza sem a força de trabalho ou sem riqueza social. Com o avanço informacional-digital destrutivo para a 
força de trabalho, esta se torna cada vez mais descartável e supérflua, sendo que o desmonte dos diretos trabalhistas e a precarização do trabalho humano vêm acompanhados de uma crise que se abateu no interior do movimento operário e sindical levando ao seu refluxo.

Em resposta à crise estrutural do capital ocorrem metamorfoses no processo de produção do capital e suas repercussões no processo de trabalho. As tentativas dessas diminuições do trabalho vivo, segundo Antunes, se expressam por meio da flexibilização, da desregulamentação, da terceirização, da informalidade e do trabalho intermitente. Nesse sentido, o capitalismo que vem se configurando nas últimas décadas acentuou sua lógica destrutiva, acirrando as alienações, as coisificações, os traços de estranhamentos, as devastações ambientais, as opressões de gênero, de raça, etnia, entre outras.

Segundo o autor, no século XXI a classe trabalhadora se fragmentou, heterogeneizou e complexificou ainda mais, principalmente com o trabalhador "polivalente e multifuncional" da era informacional, das plataformas digitais e dos aplicativos. É um mundo do trabalho no qual ocorre a "uberização do trabalho", entendida pelo autor como uma nova modalidade de servidão (ANTUNES, 2018, 2019), de precarização ilimitada, de desemprego estrutural exacerbado, de trabalhos intermitentes, acidentes, assédios, mortes e suicídios. E, no atual contexto pandêmico, o capital vem realizando ou ampliando vários "experimentos" como o teletrabalho, o home office e o ensino à distância, que visam a intensificar e potencializar, pós-pandemia, os mecanismos de exploração do trabalho nos mais diversos setores da economia, transferindo o ônus da crise à classe trabalhadora (NOGUEIRA, 2011).

Essa abordagem é fundamental considerando que vivemos em tempos de conservadorismo e de neoliberalismo, sendo que a questão social e suas expressões na vida da classe trabalhadora foram agravadas com a pandemia do SARS-Cov-2, num cenário demarcado pela crise sanitária, econômica e política, cujos desafios e contradições advindos das transformações contemporâneas afetam o mundo do tra- 
balho, seus processos e sujeitos, provocando redefinições profundas no Estado e nas políticas sociais. Isso se confirma a partir dos dados recentes da Organização Internacional do Trabalho - OIT (2021) que mostram que um ano e meio após o início da pandemia Covid-19 a crise econômica, trabalhista, de saúde e social exacerbaram os significativos déficits de trabalho e os altos níveis de desigualdade existentes na América Latina e no Caribe. E cerca de $70 \%$ dos postos de trabalho criados neste ano em países latino-americanos são em condições de informalidade, enquanto a desocupação e a baixa participação no trabalho persistem, de modo que as mulheres, jovens, migrantes, pequenas e médias empresas e trabalhadores menos qualificados experimentaram com maior intensidade os efeitos dessa crise.

O autor, de forma contundente, afırma nesta obra que a lógica societal, em seus traços dominantes, é dotada, portanto, de uma aguda destrutividade, voltada prioritariamente para a produção de mercadorias, que destrói o meio ambiente em escala globalizada, sendo a expressão mais profunda da crise que assola a (des)sociabilização contemporânea e causa mais desemprego e mais desigualdade social. No entanto, ele volta a contestar a tese do fim da centralidade do trabalho no capitalismo contemporâneo, defendida por autores "eurocêntricos" como Adam Schaff e André Gorz e outros, evidenciando que se trata de um equívoco pensar na desaparição ou no fim do trabalho até mesmo na fase atual do capitalismo pandêmico, pois entende que não é possível perspectivar nenhuma possibilidade de eliminação da classe-que-vive-do trabalho, enquanto forem vigentes os pilares constitutivos do modo de produção do capital.

Assim como em suas obras anteriores, Ricardo Antunes se opõe ao modo de produção capitalista; contudo, ele inova nesta obra ao sintetizar a fase atual de capital pandêmico, mostrando que nesta fase coexistem simultânea e imbricadamente (de forma trágica) o sistema de metabolismo antissocial do capital (sob o comando do capital financeiro), a crise estrutural e a explosão do coronavírus. Ele remete à 
estrutura da sociedade de classes, quando aponta para a injusta situação na qual a burguesia possui seus fortes instrumentos de defesa, obtendo mais segurança e mais possibilidades de fazer quarentena e o isolamento social para se evitar o contágio pelo coronavírus, enquanto que a classe-que-vive-do-trabalho luta para sobreviver. Assim, a maioria da classe trabalhadora foi posta numa encruzilhada, pois precisou renunciar ao isolamento social e à quarentena, por não possuir uma fonte alternativa de renda durante a pandemia, e teve que se submeter aos riscos do contágio em função de sua condição de trabaIho, sobretudo no caso dos desempregados, informais, trabalhadores intermitentes, uberizados, subutilizados, subocupados e terceirizados.

O autor aborda a atual pandemia como produto da dinâmica global do capitalismo e traz reflexões teóricas e interlocuções importantes para a análise da realidade concreta, na qual se revela de forma gritante as desigualdades sociais, sendo que é a classe trabalhadora a mais atingida, pois sofre com as consequências da estrutura social capitalista e da divisão sociossexual e racial do trabalho em sua nova morfologia, fazendo com que as discriminações de classe, gênero e raça se intensifiquem ainda mais, principalmente entre as trabalhadoras indígenas, imigrantes e refugiados.

Ainda que retrate os tempos atuais como uma era das trevas, o autor finaliza sua obra destacando que a pandemia do capital mostra que a invenção de um novo modo de vida deve ser um imperativo de nosso tempo. E se mantem otimista ao acreditar na construção de outro sistema de metabolismo verdadeiramente humano-social e de reinvenção do trabalho social e humano como atividade vital e livre, baseados em valores que pertencem a um ethos socialista.

O livro em tela é de suma importância para as Ciências Sociais e o Serviço Social brasileiro, visto que as problemáticas levantadas nesse livro evidenciam o caráter de classe da pandemia e reforçam que o atual panorama laboral é complexo. Trata-se de uma obra que nos faz pensar sobre a relação entre o mundo do trabalho e o atual contexto 
pandêmico, mostrando que ambos estão conectados ao sistema de metabolismo antissocial vigente, à nova morfologia do trabalho e ao cenário de crise do capital, de ataques aos direitos sociais e seus rebatimentos sobre a classe trabalhadora.

\section{Referências}

ANTUNES, Ricardo. O Privilégio da Servidão: o novo proletariado de serviços na era digital. São Paulo: Boitempo, 2018.

ANTUNES, Ricardo. (Org). Riqueza e Miséria do Trabalho no Brasil. São Paulo: Boitempo, 2019. MÉSZÁROS, István. Para além do capital: rumo a uma teoria da transição. Tradução Paulo Cezar Castanheira, Sérgio Lessa. São Paulo: Boitempo, 2002.

NOGUEIRA, Claudia M. O Trabalho Duplicado: a divisão sexual no trabalho e na reprodução. São Paulo: Ed. Expressão Popular, 3ª . Edição, 2011.

ORGANIZAÇÃO INTERNACIONAL DO TRABALHO - OIT. Empleo e informalidad en América Latina y el Caribe: una recuperación insuficiente y desigual. Serie Panorama Laboral en América Latina y el Caribe 2021. Nota técnica. Septiembre, 2021, 54p. Disponível em: <https://www.ilo.org/wcmsp5/groups/ public/---americas/---ro-lima/documents/publication/wcms_819022.pdf $>$ acesso em 14 set 2021.

\section{Nota}

1 Socióloga, mestre em Ciências Sociais pela Universidade Federal do Espírito Santo (UFES) e graduanda em Serviço Social pela UFES. E-mail: renatavb.ifes@gmail.com 